\title{
A fotografia como poesia e a poesia como fotografia. Sobre Arthur Omar e Arturo Carrera
}

\author{
Jorge Wolff*
}

\section{Resumo:}

O texto aborda a "trituração do sentido" operada pela fotografia num poema de Arturo Carrera (Coronel Pringles, Argentina, 1948), Fotografías imaginarias con nieve de verdad, e numa série de retratos de Arthur Omar (Poços de Caldas, Minas Gerais, 1948), Antropologia da face gloriosa. Trata-se em Carrera de imagens "derretidas" correspondentes às "estruturas dissipativas" que caracterizam sua poesia, segundo Laddaga, onde a linguagem é basculada em nome de uma sutil "agramaticalidade", e, em Omar, da rostidade violentada em exuberantes imagens táteis. Aos rostos expressionistas de Omar fazem contraponto a série de retratos Niños... que nacieron peinados de Alfredo Prior (Buenos Aires, 1952), que se mesclam a fragmentos de poemas de Carrera no álbum homônimo.

\section{Palavras-chave:}

Fotografia; poesia; rosto; imagem

Seja o que for o que ela dê a ver e qualquer que seja a maneira, uma foto é sempre invisível: não é ela que vemos.

Roland Barthes, A câmara clara

Com o branco dos olhos postos no invisível da imagem fotográfica, este texto não pretende propor um puro contraste, uma comparação direta entre as "poéticas fotográficas" de dois diferentes artistas-escritores de dois diferentes países, mas antes alguns acercamentos com base em certas apropriações teóricas e em três ou quatro questões e intuições. O plano de ação que o texto encerra não implica, portanto, contrastar mas compartilhar certas leituras e imagens, ou, mais precisamente: invocar as Fotos imaginarias con nieve de verdad (2008), poema longo de Arturo Carrera dedicado à nevasca que atingiu Buenos Aires no inverno de 2007, para com ele fazer "nevar" ou "respingar" sobre os rostos suados de Arthur Omar em Antropologia da face gloriosa, através por sua vez do ricochete dos rostos "de giz molhado" dos Niños... que nacieron peinados, ${ }^{1}$ série de retratos pintados em 1971 por Alfredo Prior - os mesmos que ilustrariam (e seriam ilustrados) por uma antologia de poemas de Carrera no álbum homônimo de 2007.

\footnotetext{
* Professor do PPG em Ciências da Linguagem da Universidade do Sul de Santa Catarina (UNISUL).

${ }^{1}$ Literalmente, "crianças... que nasceram penteadas".
} 

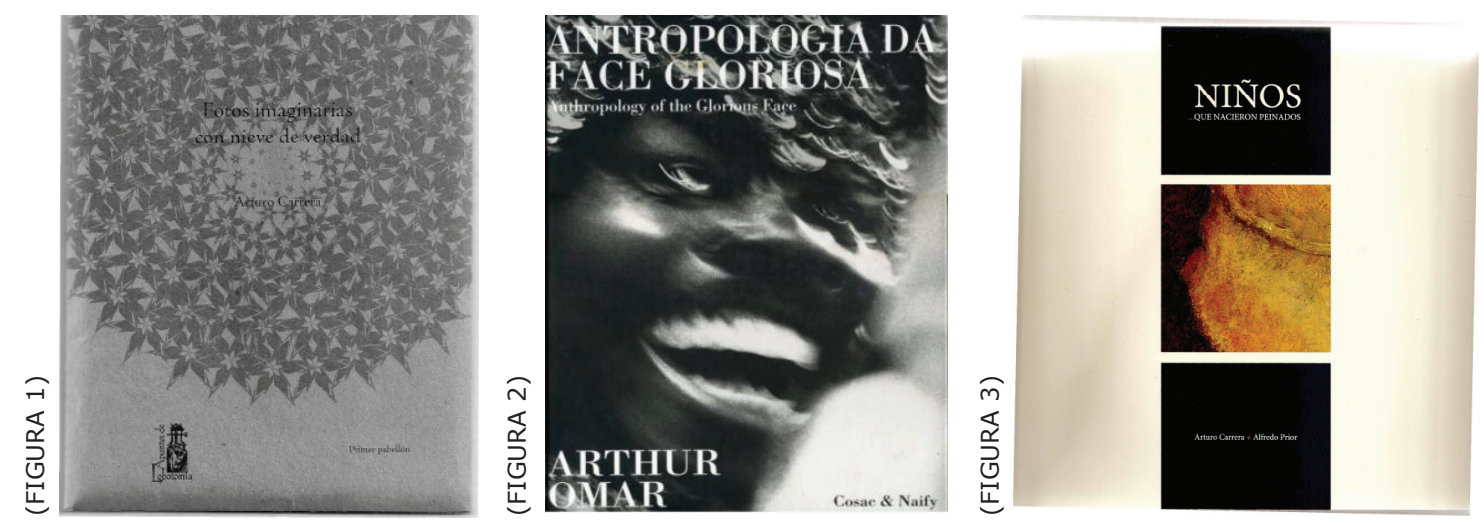

Capa Fotos imaginarias con nieve de verdad Arturo Carrera Capa Antropologia da face gloriosa ARTHUR OMAR

Capa Niños...que nacieron peinados ARTURO CARRERA e ALFREDO PRIOR

Para introduzir brevemente seus universos poéticos, escutemos duas falas - uma de Arturo Carrera (poeta nascido em 1948 em Coronel Pringles, no sul da província de Buenos Aires) e outra de Artur Omar (artista nascido no mesmo ano em Poços de Caldas, no sul do estado de Minas Gerais). As duas passagens dão um rápido vislumbre de seus modos de ver, de ler e de fazer, ambas a propósito da música e do ritmo.

Para o autor do Tratado de las sensaciones (2002), segundo o qual o "contorno da voz" é "uma sensação a mais",

A única música ou o único minimalismo musical ligado à poesia é o do ritornelo, porque é a música do território da infância. Que tem um ritmo aparente, um simulacro de ritmo. São as canções de ninar, certos poemas de Lorca, os poemas de animais de Roethke, e tantos outros exemplos. (CARRERA, 2005, p. 41)

Para o autor de O som, ou Tratado de Harmonia (1984), cuja "antropologia da face" "como prática física pertence à ordem da Música",

O artista percute, o outro soa. $O$ artista tem as baquetas, o outro é o couro, vibra. $O$ artista bate, o outro explode. Só nesse sentido se pode dizer que a fotografia tem ritmo. Não o ritmo visual dos elementos (massas, volumes, linhas) no interior de uma imagem, o que a aproximaria das artes plásticas, mas o ritmo resultante da dança entre o homem e seu tambor. Tímpano. (OMAR, 1997, p. 23)

De modo que o artista percute, o outro soa, segundo Omar, na única música da poesia que é o ritornelo, segundo Carrera. Na abordagem de Omar, a fotografia foi inventada para capturar o fotográfico e modular o tempo, nunca para fixá-lo (cf. BENTES apud OMAR, 1997, p. 10). Na de Carrera, de modo um tanto similar nesse ponto, há uma propensão "a compor seus textos um pouco como se fossem edificações destinadas a alojar frases de outros, que o poema retém, modula e recompõe" (LADDAGA, 2007, p. 2). Como isto se dá em Fotos imaginarias con nieve de verdad? 
Baseado em fatos reais - como, aliás, qualquer poema ${ }^{2}$-, a história invocada é a de uma inesperada chuva de flocos de "água queimante", que costumamos chamar de neve, depois de décadas de ausência na grande cidade. O que há de peculiar nas cenas reencenadas no poema é que as fotos da câmara digital se perderam por completo, perda total que é o mote para o eco da indagação do poeta, que poderíamos ler nos termos do "mal de arquivo" derridiano (DERRIDA, 2001), mas também nos de Georges Didi-Huberman em O que vemos, o que nos olha: "Como mostrar um vazio? E como fazer desse ato uma forma - uma forma que nos olha?" (DIDI-HUBERMAN, 1998, p. 35). O primeiro dos 28 fragmentos do poema revisita então o teatro da experiência viva da neve, registrando o que nela desaparece e não desaparece:

Porque conseguimos ver enquanto

olhávamos os flocos

o céu que parecia dizer nomes.

A alegria incontável do fundo e da forma

que tivemos muito perto quando enumerava

as chispas da cor na luz branca e

as fotos que resistiram na aparente escuridão.

Agora

está vazia a câmara e

do outro lado insistem

nossos rostos beijados pela eterna,

intrigante nevinha. ${ }^{3}$

O poema sugere, assim, que é preciso ver sem olhar, quer dizer, ver o vazio que nos olha, o "visível incrustado no tangível", na expressão de Merleau-Ponty, para quem ver também é tocar (cf. DIDI-HUBERMAN, 1998, p. 34). Ver com o branco dos olhos, diria Arthur Omar (1999, p. 41). A "trituração do sentido" operada pela fotografia e sua perda são aliadas na tarefa de modular a série de imagens "derretidas" junto com a própria neve, que correspondem por sua vez às "estruturas dissipativas" que caracterizam sua poesia, nos termos de Reinaldo Laddaga (2007, p. 21): a linguagem é basculada em nome de uma sutil "agramaticalidade da inconstância" que está intimamente ligada ao "isso-foi" barthesiano, ao tempo vivo-morto, ou a um tipo de imobilidade viva, que remete à escrita do presente, isto é, ao haikai. O haikai visto no seminário sobre $A$ preparação do romance

\footnotetext{
2 Esta afirmação supõe, obviamente, uma visão desviante em relação às convenções em torno do conceito de real.

${ }^{3}$ As fotos se perderam e a neve era de verdade; resta saber se ninguém os fotografou fotografando, como ocorreu com Hubert Damisch cujo retrato que fizera de Roland Barthes em Cerisy-la-Salle em 1977 se perdeu, o qual, no entanto, seria magicamente restituído através da foto desse mesmo ato fotográfico, feita por um conhecido, que Damisch receberia pouco depois (cf. DAMISCH, H. La dénivelée. A l'épreuve de la photographie. Paris: Seuil, 2001). A versão brasileira do poema é de minha autoria.
} 
como - escreve Barthes - "forma exemplar da Notação do Presente = ato mínimo de enunciação, forma ultra-breve, átomo de frase que anota (marca, examina, glorifica, dota de uma fama) um elemento tênue da vida 'real', presente, concomitante" (BARTHES, 2005, p. 59; trad. minha). Portanto, sendo "fruição imediata do sensível e da escritura" e dispondo "em si mesmo, por uma química específica da forma breve, a certeza do 'Isso-foi'"' (Idem, p. 118), o haikai tem relação imediata com a fotografia e - como escreve na Câmara clara - com o que denomina, com um termo emprestado da fenomenologia, de "noema da fotografia": "o traço inimitável da Fotografia (seu noema) é que alguém viu o referente (mesmo que se trate de objetos) em carne e osso, ou ainda em pessoa" (BARTHES, 1984, p. 118). Trata-se da "imobilidade viva" antes mencionada, na qual "uma explosão faz uma pequena estrela no vidro do texto e da foto", o que, segundo Laddaga (2007, p. 16), seria "uma boa descrição do imperativo que, a partir do começo da década de 1980, constitui o programa Carrera", com o livro Arturo y yo. Trata-se também do tema do "êxtase fotográfico" com o qual Barthes encerra A câmara clara.

No que diz respeito a Arthur Omar, pode-se afirmar que sua Antropologia da face gloriosa é, entre outras coisas, um mergulho na Câmara clara barthesiana, um mergulho no "êxtase fotográfico". Na conclusão do texto famoso são postos em contraste dois modos de ver a fotografia, o da "sensatez" (ou domesticação) e o da "loucura" (ou êxtase). Do primeiro modo participam, segundo ele, o cinema ficcional, "justamente o que é chamado de sétima arte", "o próprio contrário de uma alucinação; é simplesmente uma ilusão" (BARTHES, 1984, p. 172). Omar, fotógrafo convulsivo, converge também nesse ponto com Barthes em sua visão "invertida" da fotografia em relação ao cinema. Para ele, a fotografia, "esteticamente, surge depois do cinema" (cf. BENTES apud OMAR, 1997, p. 9): o cinema está, a seu ver, excessivamente próximo do real, "por ser seu mais perfeito duplo" e "só muito raramente atinge o invisível, o não-dito, o estético, o êxtase fotográfico nascido da imobilidade (de uma pequena morte da imagem)". Ou seja, Omar está falando quase nos mesmos termos da fotografia insensata, convulsiva, extática segundo A câmara clara, com a diferença de que é afirmativo e histriônico a ponto de parecer crédulo - ainda que teatralmente crédulo - em relação aos sentidos do fotográfico como arte: alguém, este "outro" hipotético, vai fatalmente entrar "em fase", como ele diz, com o expectador e a paisagem (Idem, p. 11) e atingir, ou melhor, construir o "êxtase estético" através de fotos não dos rostos mas do tempo e da morte (Idem, p. 14, 17). Afinal, o mesmo Barthes dirá que "não é pela Pintura que a Fotografia tem a ver com a arte, é pelo Teatro" (BARTHES, 1984, p. 52-53), e se isso ocorre é pela via da Morte. A esse respeito diz Barthes:

É conhecida a relação original do teatro e do culto dos Mortos: os primeiros atores destacavam-se da comunidade ao desempenharem o papel dos Mortos: caracterizar-se era designar-se como um corpo ao mesmo tempo vivo e morto: busto pintado de branco do teatro totêmico, homem com rosto pintado do teatro chinês: maquiagem à base de pasta de arroz do Katha Kali indiano, máscara do Nô japonês. Ora, é essa mesma relação que 
encontro na Foto; por mais viva que nos esforcemos por concebê-la (e esse furor de "dar vida" só pode ser a denegação mítica de um mal-estar de morte), a Foto é como um teatro primitivo, como um Quadro Vivo, a figuração da face imóvel e pintada sob a qual vemos os mortos. (Idem, p. 54)

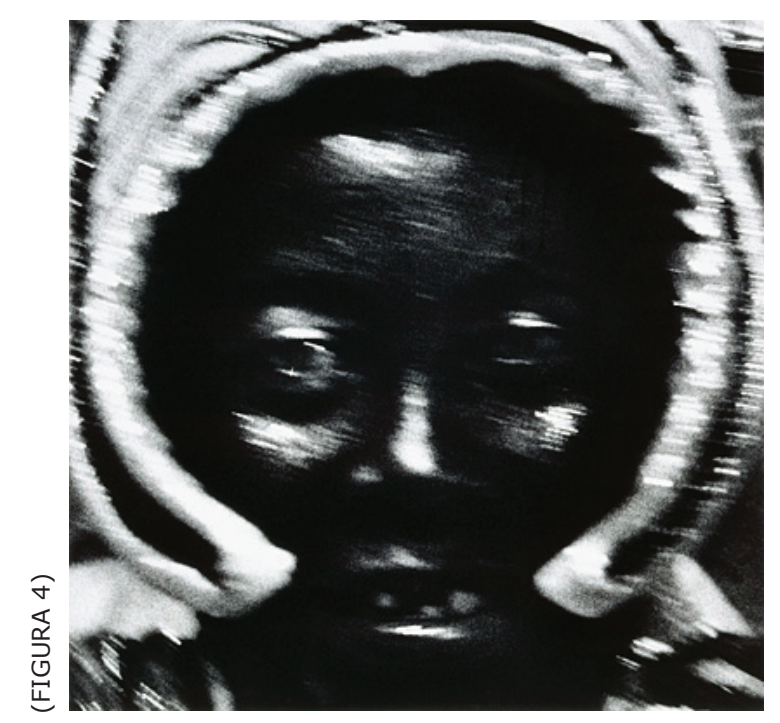

Foto Antropologia da face gloriosa ARTHUR OMAR

Pensando em Omar (FIGURA 4), vale grifar as últimas palavras de Barthes: a figuração da face imóvel e pintada sob a qual vemos os mortos. Talvez seja por isso que Gilles Deleuze e Félix Guattari, em Mil platôs, se refiram ao rosto como um "conto de terror". "Grande rosto com bochechas brancas - dizem -, rosto de giz furado com olhos como buraco negro. Cabeça de clown, clown branco, pierrô lunar, anjo da morte, santo sudário" (DELEUZE-GUATTARI, 1996, p. 32, 33). Por essa via, deslizemos até o prólogo que Arturo Carrera escreve, também em 2007, para o álbum Niños... que nacieron peinados. Trata-se, como em Mil platôs, de vida e morte, de clowns e crianças e de rostos de giz, mas de "giz molhado" nesse caso (FIGURA 5):

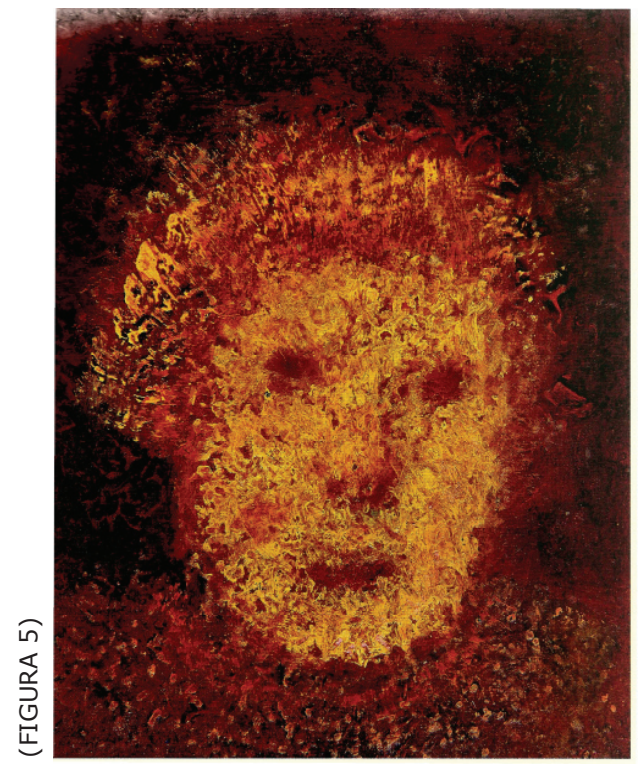

Niños... que nacieron peinados ALFREDO PRIOR 
Em 1972, Alejandra Pizarnik, duas noites antes de sua morte, conhece Prior, conhece estes retratos de crianças de Alfredo Prior que constituem a primeira série de suas pinturas, mais de cem, realizadas em Pringles em 1971. A voz grave de Alejandra trata de defini-los, de dar-Ihes outra aparência sonora - tão real entre os sonhos reais, mas tão inalcançável entre as coisas que dizemos. Diz: "Angustiam essas carinhas de giz molhado". (CARRERAPRIOR, 2007; trad. minha)

A fonte do título do álbum leva o nome de um artista central para Carrera, Henri Michaux, que em um poema chama os ideogramas chineses de "niños que nacieron peinados". O poeta argentino se apropria do título porque, escreve ele no prólogo, "penso nesta definição a cada vez que miro os retratos de Prior": "Nascer penteado tem, além das conotações estéticas que a obstetrícia lhe deu - crianças que nasciam com o cordão adornando-Ihes a cabeça -, outra que talvez as parteiras inventaram: a criança resplandece assim um destino privilegiado" (Idem). Para Daniel Link, em "Discurso sobre a infância", o álbum é "um tratado filosófico sobre o vivente e sobre a arte" que "faz da infância, a infância como déjà fait, sua pedra de toque e, ao mesmo tempo, seu ponto de aniquilamento: sabemos que toda filosofia verdadeira sonha com sua própria desaparição" (LINK, 2007; trad. minha). E, como é recorrente na poesia de Carrera, retornam ainda uma vez as vozes da infância, acompanhadas de seus brinquedos e de seus clowns - conforme igualmente ocorre nas pinturas de Prior. No sétimo fragmento do poema, as noções de tempo e de representação são matéria morta:

A similitude dizia que sim, entre os flocos

que se dispersavam. E as semelhanças que não;

inventadas por nós nas fotografias,

pareciam brancos palhaços de neve, severos,

rígidos em sua graça instantânea - porque não tinham

idade. Eram feitos da matéria de nossa

diferença. E foram nossa pena ao perceber

que se dissolve a alegria nas palavras.

Assim, quando ver é perder, as semelhanças são "inventadas por nós nas fotografias". Mesmo porque, como disse Susan Sontag, a fotografia é um modo de ver, um modo de ver que se tornou voraz e do qual vale se livrar, o que as Fotografias imaginárias sobre neve de verdade fazem a sua maneira, como, por exemplo, no fragmento 14:

Assim como se diz que um relâmpago

foi esmagado pelas rodas do carro

e o cavalo no entanto exibe intacto

a tatuagem do raio 
pelo pudor de suas imagens.

Pudorosas, assustadoras e divertidas, as imagens "derretidas" da neve - que, segundo o poema, é "a madrasta da Fotografia" - nos fazem compreender que "só a partir de sua perda / o mundo pode ser roçado e outra vez // temido". E aqui, finalmente, é possível promover o reencontro desses "fotógrafos das trevas", Arturo e Arthur que, na realidade da poesia de cada um, trocaram a fotografia pela "nictografia". No mesmo ano, 1888, em que George Eastman lança a sua "novidade radical", a Kodak portátil, Lewis Carroll inventa um aparelho que batizou de "nictógrafo". O aparelho seria, segundo Arthur Omar (1997, p. 31), "o avesso da câmera fotográfica: o nictógrafo trabalha na escuridão e se destina a fixar os pensamentos fugitivos durante a noite". Nele, uma pequena caixa, o autor de Alice no país das maravilhas escrevia sem ter que tirar as mãos de baixo das cobertas... Em Escrito com um nictógrafo, o primeiro livro de Arturo Carrera, publicado em 1972, com fundo negro e letras claras, além de forte ascendência da poesia concreta brasileira, o "aparelho" é usado em nome da "isenção de sentido, fim e princípio da linguagem, que é a prática da escritura" (CARRERA, 1972, Nota final), conforme o jargão textualista que tipificava a neo-vanguarda da época. A partir dos anos 80, livre tanto do textualismo quanto do concretismo, o poeta segue usando seu nictógrafo, já livre também do pânico que lhe causavam "as vastas superfícies brancas" (Idem), conforme o demonstra a experiência da "trituração do sentido" e do "êxtase fotográfico" sobre a branca neve.

\section{Bibliografia:}

BARTHES, Roland. A câmara clara. Nota sobre a fotografia. Trad. Júlio Castañon Guimarães. Rio de Janeiro: Nova Fronteira, 1984.

XXI, 2005.

. La preparación de la novela. Trad. Patricia Willson. Buenos Aires: Siglo

BENTES, Ivana. Arthur Omar: o êxtase da imagem. In: OMAR, A. Antropologia da face gloriosa. São Paulo: Cosac \& Naify, 1997.

CARRERA, Arturo. Escrito con un nictógrafo. Buenos Aires: Sudamericana, 1972 (republicado por Interzona Editora, 2005).

. Fotos imaginarias con nieve de verdad. México: Apuntes de Lobotomía, 2008.

e PRIOR, Alfredo. Niños... que nacieron peinados. Buenos Aires: Enargeis/ Estación Pringles, 2007.

. In: FERNÁNDEZ, Nancy. "Diálogo com Arturo Carrera". Oroboro. Revista de poesia e arte, Curitiba, jun.-jul.-ago. 2005.

DELEUZE, Gilles e GUATTARI, Félix. Mil platôs. Capitalismo e esquizofrenia vol. 3. Trad. Suely Rolnik et al. São Paulo: Editora 34, 1996.

DERRIDA, Jacques. Mal de arquivo. Uma impressão freudiana. Trad. Cláudia de Moraes Rego. Rio de Janeiro: Relume Dumará, 2001.

DIDI-HUBERMAN, Georges. O que vemos, o que nos olha. Trad. Paulo Neves. São 
Paulo: Editora 34, 1998.

LADAGGA, Reinaldo. Una poesía fotográfica. Sobre Arturo Carrera. In: CiberLetras no 16, jan. 2007. In: http://www.lehman.cuny.edu/ciberletras/v16/laddaga.html LINK, Daniel. Discurso sobre la infancia (presentación a Niños... que nacieron peinados). Buenos Aires, 2007.

OMAR, Arthur. Antropologia da face gloriosa. São Paulo: Cosac \& Naify, 1997. . O zen e a arte gloriosa da fotografia. São Paulo: Cosac \& Naify, 1999.

\title{
Title:
}

Photography as poetry and poetry as photography. On Arthur Omar and Arturo Carrera

\begin{abstract}
:
The text approaches the "grinding of the sense" performed by photography in a poem of Arturo Carrera (Coronel Pringles, Argentina, 1948), Fotografías imaginarias con nieve de verdad, and by a series of portraits by Arthur Omar (Poços de Caldas, Minas Gerais, 1948), Anthropology of the glorious face (Antropologia da face gloriosa). In Carrera it is about "melted" images corresponding to the "dissipative structures" that caracterize his poetry, according to Laddaga, whose language is tilted in the name of a subtle "agrammaticality", and, in Omar, the "faceness" violated in exuberant tactile images. To Omar's expressionist faces the series of portraits Niños... que nacieron peinados by Alfredo Prior (Buenos Aires, 1952) functions as a counterpoint, which are mixed to fragments of poems by Carrera in the album of the same title.
\end{abstract}

\section{Keywords:}

Photography; poetry; face; image 